\title{
CORRELATION OF TRISOMY 12 WITH CLINICAL FEATURES AND OTHER LABORTARY PARAMETERS IN PATIENTS WITH CHRONIC LYMPHOCYTIC LEUKAEMIA
}

\author{
Ali Ahmed, Ch Altaf Hussain*, Hamid Saeed Malik**, M Abdul Naeem***, Rafia Mehmood, Khadija \\ Armed Forces Institute of Pathology/National University of Medical Sciences (NUMS) Rawalpindi Pakistan, *CMH Institute of Medical Sciences, Bahawalpur / \\ National University of Medical Sciences (NUMS) Pakistan, **Combined Military Hospital Peshawar/ National University of Medical Sciences (NUMS) Pakistan, \\ ${ }^{* * *}$ Combined Military Hospital Lahore/ National University of Medical Sciences (NUMS) Pakistan
}

\begin{abstract}
Objective: To determine the frequency of trisomy 12 in B-Cell chronic lymphocytic leukaemia (CLL), to correlate its association with clinico-pathologic features and to determine the role of this cytogenetic defect to the prognosis.

Study Design: Cross sectional study.

Place and Duration of Study: Haematology department, Armed Forces Institute of Pathology, Rawalpindi, from May 2017 to Aug 2018.

Methodology: A total of 56 newly diagnosed patients of Chronic Lymphocytic Leukaemia were included in the study. Patients were diagnosed on the basis of National Cancer Institute Working Group guidelines. A detailed history and thorough clinical examination were performed and complete blood counts, biochemical profile, bone marrow examination, immunophenotyping on bone marrow/peripheral blood samples were done for the diagnosis of Chronic lymphocytic leukaemia. Interphase FISH studies were performed on blood/bone marrow aspiration for detection of Trisomy 12 were performed.

Results: Out of 56 patients, trisomy was detected in 12 (10.7\%) patients. Out of 7 patients with trisomy 12, five patients presented in late stages (Binet stage B and C), however this association of Trisomy 12 with Binet stage was also statistically insignificant $(p=0.474)$. About six with trisomy 12 were positive for CD 38, however this association was also not statistically significant $(p=0.124)$. Results revealed that patients having trisomy 12 underwent chemotherapy at diagnosis and during follow ups as compared to patients having other cytogenic abnormalities. Moreover, patient with trisomy 12 develop progression in disease during course of illness, however association was statistically insignificant $(p>0.05)$.

Conclusion: Most of the chronic lymphocytic leukaemia patients with Trisomy 12 were symptomatic, presented in later Binet stages (B and C), having positive CD38 status, required chemotherapy and develop progression during course of disease.
\end{abstract}

Keywords: Chronic lymphocytic leukemia, Fish, Trisomy 12.

This is an Open Access article distributed under the terms of the Creative Commons Attribution License (http://creativecommons.org/licenses/by/4.0), which permits unrestricted use, distribution, and reproduction in any medium, provided the original work is properly cited.

\section{INTRODUCTION}

In Western nations "Chronic lymphocytic leukemia (CLL)" is the most frequent kind of lymphoid malignancy, while its prevalence is relatively low in Asian countries ${ }^{1}$. According to "The American Cancer Society" 20,720 new cases of CLL were diagnosed and 3,930 deaths resulted from CLL in US in year 20192. In Pakistan, CLL comprises $5 \%$ of all the leukaemias ${ }^{3}$.

CLL is characterized by the clonal expansion of small mature looking lymphocytes with specific (CD23 \pm CD5 \pm CD19) in the bone marrow, blood and lymphoid tissues ${ }^{4-6}$. Regardless of the similar transcriptional profile, morphology and immunophenotype, CLL has considerable hereditary and clinical heterogenecity where few patients show an aggressive course with poor outcome to treatment and others patients never require treatment ${ }^{4}$.

Conventional cytogenetic analysis reveal chromo-

Correspondence: Dr Ali Ahmed, Diagnostic Centre, Pathology Lab, Combined Military Hospital Lahore Pakistan

Received: 28 Mar 2019; revised received: 10 Oct 2019; accepted: 07 Oct 2019 somal aberrations in only $40-50 \%$ of patients. However, Fluorescence in situ hybridization (FISH) analysis on interphase cells can detect chromosomal changes in approximately $80 \%$ of patients with CLL, with the most well-known being Del 13q14.3, Del 11q22.3, trisomy 12, Del 17p13.1 and Del 6q237. The most frequent cytogenetic abnormality in CLL is Del 13q14. Thetrisomy 12 is found in approximately 16\% of CLL cases and about $20 \%$ of the CLL cases have normal karyotype ${ }^{8,9}$.

Majority of the patients with trisomy 12 have morphologically different lymphocytes with uneven nuclear contours, abundant cytoplasm and prominent nucleoli ${ }^{10}$. Researchers have proposed trisomy 12 as intermediate to unfavourable prognosis ${ }^{10}$. The survival rate of patients with trisomy 12 is worse than that of patients with del 13q14 and it is better than in patients with del 11q23 or del 17p.

The objective of this study was to determine the frequency of trisomy 12 in patients with chronic lymphocytic leukaemia and its correlation with clinical and laboratory findings. As there is scarcity of local 
data available on this topic with most of the data being from western literature, so we conducted this study for our local population.

\section{METHODOLOGY}

It was a cross sectional study conducted at the department of haematology Armed Forces Institute of Pathology from May 2017 to September 2018. The ethics review committee approval was sought before the conduct of study. A total 56 patients newly diagnosed as B-CLL of all ages and either gender were enrolled in the study. Patient were diagnosed as CLL as per National Cancer Institute Working Guidelines for CLL (Lymphocytosis $>5 \times 10^{9} / \mathrm{L}$ and characteristic immunophenotype (CD19 ${ }^{ \pm}, \mathrm{CD} 5^{ \pm}, \mathrm{CD} 23^{ \pm}, \mathrm{CD} 20$ weak positive and weak expression of either kappa or lambda). The non-probability consecutive sampling technique was employed. Patients who were already on treatment and patients who lost to follow up were excluded from the study.

A detailed history and thorough clinical examination were performed and complete blood counts, biochemical profile, bone marrow examination, immunophenotyping on bone marrow/peripheral blood samples were done for the diagnosis of Chronic lymphocytic leukaemia. Interphase FISH studies were performed on blood/bone marrow aspiration for detection of Trisomy 12 and other cytogenetic abnormalities. Clinico-pathological features of patients with Trisomy 12 were compared with those of other cytogenetic abnormalities. SPSS-23 was used to analyze data. The Laboratory parameters, WBC count, $\mathrm{Hb}$ levels, Platelet count, CD-38 and ZAP-70 status were examined alongwith personal and BINET stage data. Patients were followed up (mean follow up-12 months) for disease progression or dependence of chemotherapy. The progression of disease here was defined as stage progression, increase in B2 microglobulinand Lymphocyte Doubling Time $<12$ months.

Flourescent in Situ Hybridization analysis: Blood and bone marrow specimens were analyzed through interphase FISH studies. Specimen was collected and cultured at $37^{\circ} \mathrm{C}$ in two intervals for 24 hours then after adding 200ul colchicine for $1 \mathrm{hr}$ and centrifuged at $1500 \mathrm{rpm}$ for $8 \mathrm{~min}$. Afterwards, slide was prepared for FISH study. The slide underwent further procedures such as Meta system XL DLEU/LAMP/12CEN probe, denaturation at $74^{\circ} \mathrm{C}$ for $5 \mathrm{~min}$, hybridization at $37^{\circ} \mathrm{C}$ for $18 \mathrm{hrs}$ and co-denaturation at $74^{\circ} \mathrm{C}$. The slide was washed and air dried. 10 to $20 \mathrm{ul}$ of DAPI-2 counter stain was added and it was frozen at $-20^{\circ} \mathrm{C}$ for
1 day. A total of 500 nuclei were analyzed per probe set using a fluorescent microscope with an orange green spectrum filter. Positive trisomy 12 was denoted by three green signals and two orange signals (fig-1).

Data was entered and analyzed by SPSS-23. Descriptive statistics such as mean \& SD was computed for numeric variables whereas frequencies and percentages were computed for qualitative variables. The chi-square test was applied between the variables. $p$ value $<0.05$ was taken as statistically significant.

\section{RESULTS}

A total of 56 patients were included in the study with age ranged between 38-87 years. The median age of the patients with CLL was 60 years. Manypatients $45(80.4 \%)$ were males and $11(19.6 \%)$ were females with a male to female ratio of 4:1. Majority of them were diagnosed incidentally on routine blood counts. Presenting signs and symptoms, blood counts \& staging are shown in table-I. About 28 patients had Binet stage A, 23 had Binet stage B \& 5 had stage C. CD38 expression was positive in 33 cases. ZAP 70 was negative in all cases.

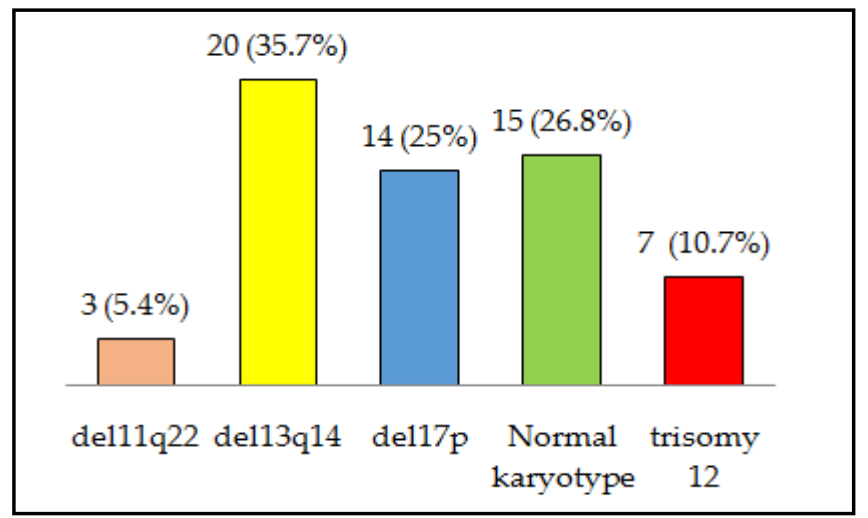

Figure: Freqjuency distribution of cytogenetic abnormalities.

Out of 56 patients, 20 patients had deletion 13q14 $(35.7 \%)$ in CLL patients, followed by normal karyotype in 15 patients $(26.8 \%)$, del17q in 14 patients $(25 \%)$, trisomy 12 in 7 cases $(10.7 \%)$ \& del11q22 in 3 patients (5.4\%) (figure).

The mean age showed statistically significant difference when compared with trisomy 12 and without trisomy $12(p=0.048)$. Out of 7 patients with trisomy 12 , five patients presented in late stages (Binet stage $B$ and $C$ ), however this association of Trisomy 12 with Binet stage was also statistically insignificant $(p=0.474)$. About six with trisomy 12 were positive for CD38, however this association was also not statistically significant $(p=0.124)$ (table-II). 
These patients were followed up for progression of disease and chemotherapy dependence for 14 months. Results revealed that patients having trisomy 12 underwent chemotherapy at diagnosis and during follow up more frequently as compared to patients having other cytogenetic abnormalities. Moreover, results showed statistically insignificant ( $p$-value $>0.05$ ) relationship of trisomy 12 with disease progression and chemotherapy dependence during course of disease (table-III).

\begin{tabular}{|c|c|}
\hline Variables & Statistics \\
\hline Quantitative & Mean \pm SD \\
\hline Age in years & $60.01 \pm 9.68$ \\
\hline WBC $\left(\times 10^{9} / \mathrm{L}\right)$ & $106.42 \pm 81.52$ \\
\hline $\operatorname{ALC}\left(x 10^{9} / \mathrm{L}\right)$ & $92.86 \pm 78.50$ \\
\hline $\mathrm{Hb}(\mathrm{g} / \mathrm{dl})$ & $11.02 \pm 2.33$ \\
\hline Platelets (x 109/L) & $164.26 \pm 92.29$ \\
\hline Qualitative & n $(\%)$ \\
\hline \multicolumn{2}{|l|}{ Gender } \\
\hline Male & $45(80.4 \%)$ \\
\hline Female & $11(19.6 \%)$ \\
\hline \multicolumn{2}{|l|}{ Clinical \& Physical Presentation } \\
\hline Asymptomatic (Incidental finding) & $22(5.3 \%)$ \\
\hline Cellulitis (Rt Forearm) & $2(3.5 \%)$ \\
\hline Chest Infection & $2(3.5 \%)$ \\
\hline Chest Pain & $1(1.7 \%)$ \\
\hline Fever & $22(39.2 \%)$ \\
\hline Weakness & $5(8.9 \%)$ \\
\hline Incidental findings & $19(33.9 \%)$ \\
\hline Progression pallor & $1(1.7 \%)$ \\
\hline Weight loss & $7(12.5 \%)$ \\
\hline Respiratory tract infection & $1(1.7 \%)$ \\
\hline Headache & $2(3.5 \%)$ \\
\hline Lymphadenopathy & $35(62.5 \%)$ \\
\hline Splenomegaly & $6(10.7 \%)$ \\
\hline Hepatomegaly & $1(1.8 \%)$ \\
\hline \multicolumn{2}{|l|}{ Binet Stage } \\
\hline A & $28(50 \%)$ \\
\hline $\mathrm{B}$ & $5(8.9 \%)$ \\
\hline $\mathrm{C}$ & $23(41.1)$ \\
\hline CD38 & $33(58.9 \%)$ \\
\hline ZAP70 & - \\
\hline
\end{tabular}

\section{DISCUSSION}

In the current study we have assessed 56 patients with CLL. The average age of the patients was 60.01 \pm 9.68 ranging from 38-87 years. Gunawardana et al. Evaluated the clinical and biological characteristics in Asian \& White patients with CLL and reported the median age of patients as 70 (25-92) years in Whites while 61 (29-85) years in Asians ${ }^{11,12}$. In a local study conducted by Rashid et al, the reported mean age of the patients was $65.8 \pm 1.5$ years and majority of the patients belonged to 71-80 years age group 3 . In another study, Ehsan et al, found the average age as 62.84 years in the patients with CLL ${ }^{13}$. This shows that more or less age distribution in CLL patients is almost same among different populaces and is certainly a disease of

Table-II: Clinico-pathological features with trisomy 12 and without trisomy 12.

\begin{tabular}{|c|c|c|c|}
\hline \multirow[b]{2}{*}{ Variables } & \multicolumn{2}{|c|}{ Trisomy 12} & \multirow{2}{*}{$\begin{array}{c}p- \\
\text { value }\end{array}$} \\
\hline & $\begin{array}{l}\text { With } \\
(n=7)\end{array}$ & $\begin{array}{c}\text { Without } \\
(\mathrm{n}=49)\end{array}$ & \\
\hline \multicolumn{4}{|l|}{ Age Groups } \\
\hline$\leq 50$ years & $3(30 \%)$ & $7(70 \%)$ & \\
\hline$>50$ years & $4(8.7 \%)$ & $42(91.3 \%)$ & 0.605 \\
\hline Mean (SD) & $53.28(9.51)$ & $60.97(9.41)$ & 0.048 \\
\hline \multicolumn{4}{|l|}{ Gender } \\
\hline Male & $6(13.3 \%)$ & $39(86.7 \%)$ & \multirow{2}{*}{0.703} \\
\hline Female & $1(9.1 \%)$ & $10(90.9 \%)$ & \\
\hline \multicolumn{4}{|l|}{ Hb Levels } \\
\hline$\leq 12 \mathrm{~g} / \mathrm{dl}$ & $6(17.1 \%)$ & $29(82.9 \%)$ & \multirow{2}{*}{0.175} \\
\hline$>12 \mathrm{~g} / \mathrm{dl}$ & $1(4.8 \%)$ & $20(95.2 \%)$ & \\
\hline Mean(SD) & $1.14(0.37)$ & $1.40(0.49)$ & 0.181 \\
\hline \multicolumn{4}{|l|}{ WBC Level } \\
\hline$\leq 150\left(\times 10^{9} / \mathrm{L}\right)$ & $7(15.9 \%)$ & $37(84.1 \%)$ & \multirow{2}{*}{0.14} \\
\hline$>150\left(\times 10^{9} / \mathrm{L}\right)$ & - & $12(100 \%)$ & \\
\hline Mean (SD) & $1.00(0.001)$ & $1.24(0.43)$ & 0.145 \\
\hline \multicolumn{4}{|l|}{ ALC Level } \\
\hline$\leq 150\left(\times 10^{9} / \mathrm{L}\right)$ & $7(15.2 \%)$ & $39(84.8 \%)$ & \multirow{2}{*}{0.187} \\
\hline$>150\left(\times 10^{9} / \mathrm{L}\right)$ & - & $10(100 \%)$ & \\
\hline Mean(SD) & $1.00(0.001)$ & $1.20(0.40)$ & 0.194 \\
\hline \multicolumn{4}{|l|}{ Platelet Count } \\
\hline$\leq 150\left(\times 10^{9} / \mathrm{L}\right)$ & $4(12.1 \%)$ & $29(87.9 \%)$ & \multirow{2}{*}{0.918} \\
\hline$>150\left(\times 10^{9} / \mathrm{L}\right)$ & $3(13 \%)$ & $20(87 \%)$ & \\
\hline Mean(SD) & $1.42(0.53)$ & $1.40(0.49)$ & 0.92 \\
\hline \multicolumn{4}{|l|}{ CD38 } \\
\hline Positive & $6(18.2 \%)$ & $27(81.8 \%)$ & \multirow{2}{*}{0.124} \\
\hline Negative & $1(4.3 \%)$ & $22(95.7 \%)$ & \\
\hline \multicolumn{4}{|l|}{ ZAP70 } \\
\hline Positive & - & - & \multirow{2}{*}{$\mathrm{N} / \mathrm{A}$} \\
\hline Negative & $7(12.5 \%)$ & $49(87.5 \%)$ & \\
\hline \multicolumn{4}{|l|}{ Binet Stage } \\
\hline A & $2(7.1 \%)$ & $26(92.9 \%)$ & \multirow{3}{*}{0.474} \\
\hline $\mathrm{B}$ & $1(2 \%)$ & $4(80 \%)$ & \\
\hline $\mathrm{C}$ & $4(17.4 \%)$ & $19(82.6 \%)$ & \\
\hline
\end{tabular}

Table-III: Relationship of trisomy 12 with disease progression and chemotherapy dependence.

\begin{tabular}{c|c|c|c|c}
\hline & \multicolumn{2}{|c|}{ Trisomy 12 } & \multirow{2}{*}{ Total } & \multirow{2}{*}{$p$-value } \\
\cline { 2 - 4 } & Yes & No & & \\
\hline \multicolumn{3}{c}{ Progression Disease } & & \multirow{2}{*}{0.666} \\
\hline Yes & 5 & 24 & 29 & \\
\hline No & 2 & 25 & 27 & \multirow{2}{*}{0.666} \\
\hline Chemotherapy Dependence & 24 & 29 & \\
\hline Yes & 5 & 24 & 27 & \\
\hline No & 2 & 25 & & \\
\hline
\end{tabular}


older age. In this study, majority of patients were males $(80.4 \%)$ whereas $19.6 \%$ were females. In the study by Chan et al, showed similar results with respect to gender i.e. males were $(73 \%)$ and females $(27 \%)^{14}$. Similar results were found in the study by Ehsan et al, with a male to female ratio of $4.6: 1^{13}$. Another study showed that males constitute $42 \%$ in Whites as compared to $53 \%$ in Asians ${ }^{12}$.

Hence male gender, is an established potential risk factor for the development of CLL. One of the serious conditions related with increased morbidity and worse prognosis is anemia among CLL patients. In our study the mean $\mathrm{Hb}$ level was $11.02 \pm 2.33 \mathrm{~g} / \mathrm{dl}$, the WBC $\left(\times 10^{9} / \mathrm{L}\right)$ was $106.42 \pm 81.52$, ALC $\left(\times 10^{9} / \mathrm{L}\right)$ was $92.86 \pm 78.50 \&$ Platelets count $(x$ 109/L) was $164.26 \pm 92.29$. Almost similar findings were observed in the study conducted at Karachi, Pakistan which showed mean hemoglobin level as $10.8 \pm 2.4 \mathrm{~g} / \mathrm{dl}$ with platelets $197.8 \pm 103.2 \times 10^{9} / \mathrm{L} \&$ TLC as $91.5 \pm 87.8$ $x 10^{9} / \mathrm{L}^{15}$. Another study showed mean $\mathrm{Hb}$ level as $9.8 \mathrm{~g} / \mathrm{dl} \pm 2.62$. TLC was divided into groups which showed that majority of the CLL patients in the range of $50000-100000 \times 10^{9} / \mathrm{L}$ and in their study about $71.3 \%$ of the patients had Platelet count of $>00 \times 10^{9} / \mathrm{L}^{3}$.

In the present study, the most common presentation of CLL patients is lymphadenopathy (62.5\%), however splenomegaly and hepatomegaly were observed in $10.7 \%$ and $1.8 \%$ of the cases. About $39.9 \%$ of the patients presented with fever and $33.9 \%$ of the patients had incidental findings.

In a study conducted by Dabaghao et al. Fever was reported as the most frequent presentation $(48 \%)$ and $73 \%$ of the patients had hepatomegaly on examination ${ }^{16}$. In another study, fever was present in $26 \%$ of the cases, jaundice in $23 \%$, hepatomegaly in $19 \%$ and lymphadenopathy in $8 \%{ }^{17}$. Rashid et al, found splenomegaly in $87.3 \%$ \& lymphadenopathy in $62.7 \%$ of the CLL patients ${ }^{3}$.

One of the clinical staging systems is Binet staging system which is used to evaluate the prognosis of CLL patients. In the present study, majority of the patients had Binet stage A (50\%), followed by stage C $(41.1 \%)$ and stage B (8.9\%). Almost similar findings were observed in study conducted among Chinese population, which showed that most of the patients had Binet stage A $(56.1 \%)$ followed by stage C $(22.2 \%)$ and stage B $(21.7 \%)^{14}$. However in another study, majority of the patients with CLL had Binet stage C (20 cases), 7 patients had stage $\mathrm{A} \& 4$ patients had stage $\mathrm{B}^{14}$.
In the last few years it has been observed that CLL patients with unmutated immunoglobulin heavy chain gene (IgHV) usually have shorter survival rate and more aggressive disease ${ }^{18}$. CD38 is a reliable and useful marker which is associated with CLL because usally it remains stable over time, even after chemotherapy, and it can be estimated easily in flow cytometry laboratories ${ }^{11}$. CD38 was found to be correlated with IgHV mutational status ${ }^{19}$. Recently, ZAP70, a member of syk family protein tyrosine kinases (PTKs); which shows an important part in T-cell development and T-cell antigen receptor (TCR), has shown association with B-cell receptor in CLL patients 20,21 . Hence, CD38 and ZAP70 are the significant prognostic markers in patients with CLL22. In the present study, CD38 expression was positive in $33 \%$ of cases, however ZAP 70 was negative in all the patients. However, in another research $42.5 \%$ of the patients with CLL showed high levels of CD38 and $47.5 \%$ of the patients were ZAP-70 positive ${ }^{23}$. In a study conducted at India, CD38 \& ZAP-70 positivity were reported in $36 \%$ and $25 \%$ of the patients respectively ${ }^{24}$.

FISH is one of the most powerful and widely used prognostic tools in patients with CLL and the third most common cytogenetic abnormality in CLL is trisomy $12^{25}$. Döhner et al. proposed hierarchical prognostic model in which trisomy 12 was labelled as an intermediate risk marker. In the present study, trisomy 12 was detected in $10.7 \%$ of the patients with CLL. In a study conducted by El-Kinawy et al, trisomy 12 was detected in $19.3 \%$ of the patients ${ }^{23}$. Bagir et al, detected trisomy 12 in 36 cases. However, the patients with trisomy 12 had better overall survival rate as compared to patients with del (11q23) or del (17p) while it is poorer as compared to patients with del $(13 q 14)^{11}$.

In this study, we have stratified trisomy 12 with respect to age, gender, blood laboratory findings, ZAP 70 and CD38. However, no significant statistical association was found between stratified groups $(p>0.05)$. In a study by Matutes et al, about $18 \%$ of the patients had trisomy 12, majority of those patients were males 28 , and most of them had Binet stage A (64\%). In this study majority of patients with trisomy 12 were males ( 6 cases), $100 \%$ of the patients had WBC $\leq 150$ (x109/L), $85.7 \%$ of the patients had positive CD38, none of the patient had ZAP70 and $57.1 \%$ of them had Binet stage C. In another study conducted by Abruzzo et al, majority of the CLL patients with trisomy 12 were males $(80 \%)$, had WBC $\leq 150 \mathrm{~L} / \mathrm{G}(75 \%)$, ZAP positive in $62 \%$ 
and CD38 $<30 \%$ in $67 \%$ of the cases. Riches et al. found CLL patients with trisomy 12 had statistically significant expression of CD38 as compared to other major cytogenetic abnormalities $(p<0.01)$.

In this study, 5 CLL patients with trisomy 12 were chemotherapy dependent and showed progression of disease. Among them 1 patient died during the follow up period of 1 year. Sagatys et al, observed in their study that survival rate of CLL patients with trisomy 12 is poorer as compared to patients with del (13q14) and it is better in patients with del (11q23) or del (17p).

\section{CONCLUSION}

Frequency of trisomy 12 was found to be 7 $(10.7 \%)$. Most of the CLL patients with Trisomy 12 were symptomatic, presented in later Binet stages (B and $\mathrm{C}$ ), having positive CD38 status, required chemotherapy and develop progression during course of disease. Therefore, this cytogenetic abnormality may be associated with unfavourable prognosis. The insignificant associtation when comparing with patients without trisomy 12 is due to presence of other unfavourable markers (Del 17p and 11q22) in that group. So Investigation of Trisomy 12 by FISH should therefore be included in the panel of prognostic markers in patients with chronic lymphocytic leukaemia.

\section{CONFLICT OF INTEREST}

This study has no conflict of interest to be declared by any authors.

\section{REFERENCES}

1. Kawamata N, Moreilhon C, Saitoh T, Karasawa M, Bernstein BK. Genetic differences between Asian and Caucasian chronic lymphocytic leukemia. Int J Oncol 2013; 43(2): 561-65.

2. Muzii L, Bellati F, Bianchi A, Palaia I, Manci N, Zullo MA, et al. Laparoscopic stripping of endometriomas: a randomized trial on different surgical techniques. Part II: pathological results. Hum Reprod 2005; 20(7): 1987-92.

3. Rashid U, Somayya Virk Hr, Rashid A, Zia R. Haematologic complications in chronic lymphocytic leukemia. Pak J Med Health Sci. 2018; 12(1): 352-54.

4. Darwiche W, Gubler B, Marolleau JP, Ghamlouch H. Chronic Lymphocytic Leukemia B-Cell Normal Cellular Counterpart: Clues From a Functional Perspective. Front Immunol 2018; 9(1): 683-85.

5. Kipps TJ, Stevenson FK, Wu CJ, Croce CM, Packham G, Wierda WG, et al. Chronic lymphocytic leukaemia. Nat Rev Dis Primers. 2017; 3(2): 16096-99.

6. Fabbri G, Dalla-Favera R. The molecular pathogenesis of chronic lymphocytic leukaemia. Nat Rev Cancer 2016; 16(3): 145-62.

7. Puiggros A, Blanco G, Espinet B. Genetic abnormalities in chronic lymphocytic leukemia: where we are and where we go. Biomed Res Int 2014; 2014(1): 435983-85.
8. Roos-Weil D, Nguyen-Khac F, Chevret S, Touzeau C, Roux C, Lejeune J, et al. Mutational and cytogenetic analyses of 188 CLL patients with trisomy 12: A retrospective study from the French Innovative Leukemia Organization (FILO) working group. Genes Chromosomes Cancer 2018; 57(11): 533-40.

9. Parker TL, Strout MP. Chronic lymphocytic leukemia: prognostic factors and impact on treatment. Discov Med 2011; 11(57): 115-23.

10. Anastasi J, Le Beau MM, Vardiman JW, Fernald AA, Larson RA, Rowley JD. Detection of trisomy 12 in chronic lymphocytic leukemia by fluorescence in situ hybridization to interphase cells: a simple and sensitive method. Blood 1992; 79(7): 1796-801.

11. Sagatys EM, Zhang L. Clinical and laboratory prognostic indicators in chronic lymphocytic leukemia. Cancer Control 2012; 19(1): 18-25.

12. Gunawardana C, Austen B, Powell JE, Fegan C, Wandroo F, Jacobs A, et al. South Asian chronic lymphocytic leukaemia patients have more rapid disease progression in comparison to White patients. Br J Haematol 2008; 142(4): 606-9.

13. Ehsan A LA, Khan MA. Autoimmune complications in chronic lymphocytic leukemia: a single center experience. Biomedica 2013; 29(1): 37-41.

14. Chan TS, Lee YS, Del Giudice I, Marinelli M, Ilari C, Cafforio L, et al. Clinicopathological features and outcome of chronic lymphocytic leukaemia in Chinese patients. Oncotarget 2017; 8(15): 25455-68.

15. Zeeshan R, Sultan S, Irfan SM, Kakar J, Hameed MA. Clinicohematological profile of patients with B-chronic lymphoid leukemia in Pakistan. Asian Pac J Cancer Prev 2015; 16(): 793-96.

16. Dabadghao VS, Diwan AG, Raskar AM. A clinicohaematological profile of splenomegaly. Bombay Hospital J 2012; 54(5): 10-12.

17. Humaira M, Ahmed A, Memon A, Siddique SA, Hayee PA, Ghani $\mathrm{MH}$, et al. Etiological Pattern of Splenomegaly in Adults at Tertiary Care Hospital Jamshoro Sindh. J Liaquat Uni Med Health Sci 2016; 15(1): 40-45.

18. Rozovski U, Keating MJ, Estrov Z. Why Is the Immunoglobulin Heavy Chain Gene Mutation Status a Prognostic Indicator in Chronic Lymphocytic Leukemia?. Acta Haematol 2018; 140(1): 51-54.

19. Malavasi F, Deaglio S, Damle R, Cutrona G, Ferrarini M, Chiorazzi N. CD38 and chronic lymphocytic leukemia: a decade later. Blood 2011; 118(13): 3470-78.

20. Frushicheva MP. Abstract A24: ZAP-70 and SYK regulation in the B cell receptor pathway in chronic lymphocytic leukemia. AACR; 2017; 100(13): 4609-14.

21. Chen L, Widhopf G, Huynh L, Rassenti L, Rai KR, Weiss A, et al. Expression of ZAP-70 is associated with increased B-cell receptor signaling in chronic lymphocytic leukemia. Blood 2002; 100(13): 4609-14.

22. Parikh SA, Shanafelt TD. Prognostic factors and risk stratification in chronic lymphocytic leukemia. Semin Oncol 2016: 43(2): 233-40.

23. El-Kinawy NS, Sharaf HM, El-Hamid MA. Prognostic significance of del 17p, ZAP-70 and CD38 as independent indicators for B-CLL: correlation to response to treatment and disease outcome. Egypt J Med Human Genet 2012; 13(2): 173-81.

24. Gogia A, Sharma A, Raina V, Kumar L, Gupta R, Kumar R. Prevalence of ZAP-70 and CD 38 in Indian chronic lymphocytic leukemia patients. Ind J Cancer 2013; 50(4): 333-36.

25. Puiggros A, Blanco G, Espinet B. Genetic abnormalities in chronic lymphocytic leukemia: where we are and where we go. Bio Med Res Int 2014; 2014(1): 13-15. 